\title{
Meta analysis of angiotensin-converting enzyme I/D polymorphism as a risk factor for preeclampsia in Chinese women
}

\author{
W.G. Zhong ${ }^{1}$, Y. Wang ${ }^{2}$, H. Zhu' ${ }^{1}$ and X. Zhao ${ }^{1}$ \\ ${ }^{1}$ Shanghai Putuo Maternity and Infant Health Hospital, Shanghai, China \\ ${ }^{2}$ Shanghai Institute of Hypertension, Ruijin Hospital, \\ Shanghai Jiaotong University School of Medicine, Shanghai, China \\ Corresponding author: W.G. Zhong / Y. Wang \\ E-mail: zhong_weiguo@sina.com / yanwangshjd@yahoo.cn
}

Genet. Mol. Res. 11 (3): 2268-2276 (2012)

Received August 19, 2011

Accepted January 12, 2012

Published May 21, 2012

DOI http://dx.doi.org/10.4238/2012.May.21.1

\begin{abstract}
Preeclampsia affects 3-8\% of pregnancies and is a major cause of maternal and perinatal morbidity and mortality worldwide. Inappropriate activation of the renin-angiotensin system may play a role in the development of preeclampsia. An insertion/ deletion polymorphism in the angiotensin-converting enzyme gene (ACE-I/D) has been associated with differences in ACE activity. However, there are controversies in reports on the association of ACEI/D with preeclampsia. Data were analyzed using Review Manager Version 5.0 and a random effects model was applied irrespective of between studies heterogeneity, which was evaluated via sensitivity and subgroup analyses. Publication bias was evaluated using the fail-safe number. A systematic search was performed based on published case control studies up to October 1, 2011, and 11 studies were included, involving 800 patients and 949 controls. Significant association of the $A C E \mathrm{D}$ allele with increase risk of preeclampsia was found (odds ratio $=1.93,95 \%$ confidence interval $=1.19-3.12 ; \mathrm{P}=0.008)$. Sensitivity analysis showed that no individual study had an undue influence on the
\end{abstract}


summary odds ratios for all contrasts. An analysis stratified by study size showed an attenuated odds ratio towards a null effect as study size increased. Based on our meta-analysis, we suggest that the D allele of the $A C E$ gene is related with increased risk for preeclampsia in the Chinese population. Considering the potential existence of small study bias, further research should be performed with a larger dataset.

Key words: ACE; Insertion/deletion polymorphism; Preeclampsia

\section{INTRODUCTION}

Preeclampsia (PE) is a pregnancy-related disorder characterized by hypertension and proteinuria after 20 weeks of gestation. It affects approximately 3-8\% of pregnancies worldwide and is a significant source of maternal and perinatal mortality and morbidity (WHO, 2005). A familial predisposition to PE has been documented, and both men and women who were the offspring of a pregnancy complicated by $\mathrm{PE}$ are significantly more likely to have a pregnancy complicated by PE (Esplin et al., 2001). Although a genetic susceptibility to PE has been established with both maternal and fetal genes and a number of association studies have been performed, the results are inconsistent, and the causative genes involved in PE have yet to be identified (He et al., 2009; Tan et al., 2009).

The rennin-angiotensin-aldosterone system is a hormone system that regulates blood pressure and water balance, which play a role in the development of many cardiovascular disorders, including PE (Schmieder et al., 2007). When blood volume is low, angiotensinconverting enzyme (ACE) hydrolyzes angiotensin I to angiotensin II, a strong vasoconstrictor, increasing blood pressure (Admiraal et al., 1990). A common 287-bp Alu repeat sequence insertion or deletion (I/D) within intron 16 in the $A C E$ gene has been reliably associated with substantial differences in the plasma ACE concentration, whereas the mean plasma ACE level of DD subjects was about twice that of II individuals (Tiret et al., 1992). Thus, the polymorphism has been considered a strong candidate for PE risk; however, a number of contradictory findings have been reported (Rohacs et al., 1997; Bouba et al., 2003; Galao et al., 2004; Kaur et al., 2005). The inconsistency of results has been attributed to insufficient statistical power caused by small sample size. Meta-analysis, a powerful approach that pools the results of independent analyses, can increase statistical power and resolution. We, therefore, conducted a comprehensive meta-analysis of all available data regarding the association between $A C E$ I/D gene polymorphism and PE risk in the Chinese women to estimate the strength of genetic association, explore the sources of heterogeneity through predefined sensitivity and subgroup analyses, and discuss the limitations of the studies.

\section{MATERIAL AND METHODS}

\section{Literature search and inclusion criteria}

Electronic databases such as PubMed, Embase, China Biological Medicine Database, China National Knowledge Infrastructure, and Wanfang were used to search for publications with the key words "preeclampsia (PE) or pregnancy induced hypertension (PIH)" and "angio- 
tensin converting enzyme or ACE" combined with "gene or variant or polymorphism or allele" with the last update of October 1, 2011. If multiple publications had been produced from the same study population, the report with the largest sample size was selected. Studies that we selected satisfied the following criteria: 1) evaluated the association of PE and the $A C E$ gene 287bp alu repeat sequence I/D within intron $16 ; 2$ ) performed a case-control study using a hospital- or population-based design; 3 ) provided sufficient information on genotype counts between PE patients and controls for estimating odds ratio (OR) and its corresponding $95 \%$ confidence interval $(95 \% \mathrm{CI}) ; 4)$ did not deviate from Hardy-Weinberg equilibrium in controls; and 5) was published in English and Chinese languages and performed in Chinese Han populations.

\section{Extracted information}

All articles were reviewed and separately collated by two independent investigators (W.G. Zhong and H. Zhu). Any discrepancies were adjudicated by a discussion until a consensus was reached. The information extracted from each literature study included the first author, year of publication, region, match method, baseline characteristics of the study population, and genotype distribution in patients and controls.

\section{Statistical analysis}

The strength of the association between the $A C E \mathrm{I} / \mathrm{D}$ gene polymorphism and PE was estimated using pooled ORs, with the corresponding $95 \% \mathrm{CI}$ estimated using the Z-test. The heterogeneity assumption was checked using the chi-square-based Q-test (significance set at $\mathrm{P}<0.05$ ). Because the heterogeneity of the studies in our analysis was significant, the pooled OR was estimated using the random-effects model (DerSimonian and Laird method). Studies were also categorized into subgroups based on region and sample size. The statistical analyses were performed using SPSS 13.0 for Windows (SPSS Inc., Chicago, IL, USA) and Review Manager Version 5.0 (Revman, The Cochrane Collaboration, Oxford, UK).

The fail-safe number $\left(\mathrm{N}_{\mathrm{fs}}\right)$ was used to estimate the publication bias. In this study, the $\mathrm{N}_{\mathrm{fs}}$ significance was established as follows: $\mathrm{N}_{\mathrm{fs} 0.05}=(\Sigma \mathrm{Z} / 1.64)^{2}-\mathrm{k}$ (where $k$ is the number of articles included in each meta-analysis). The meta-analysis result was considered to have a significant publication bias when $\mathrm{N}_{\mathrm{fs}}$ was smaller than the number of observed studies.

Sensitivity analysis was undertaken through repeated removal of one study for every iteration to show the impact of that study on the combined effect. Likewise, cumulative analysis was performed according to the ascending date of publication to show how the evidence shifted over time.

\section{RESULTS}

\section{Study characteristics and meta-analysis results}

In accordance with the inclusion criteria, 11 studies with $800 \mathrm{PE}$ patients and 949 controls were analyzed. The basic characteristics of the study populations are presented in Table 1. The participants were recruited from 11 cities, among which five were from northern China (Zhu et al., 1998; Huang et al., 2001; Bai et al., 2002; Wu et al., 2002; Chen et al., 2006) and 
six from southern China (Zhou et al., 1999; Gao et al., 2002; Shang et al., 2003; Mao et al., 2004; Wang et al., 2004; Yan et al., 2011). For all studies, the genotype distributions of $A C E$ I/D polymorphism satisfied Hardy-Weinberg equilibrium in controls at the level of 0.05 . However, the cases in three studies deviated from Hardy-Weinberg equilibrium. The frequencies of the $A C E \mathrm{D}$ allele ranged widely from 31.7 to $75.7 \%$ in cases and from 28.0 to $81.5 \%$ in controls.

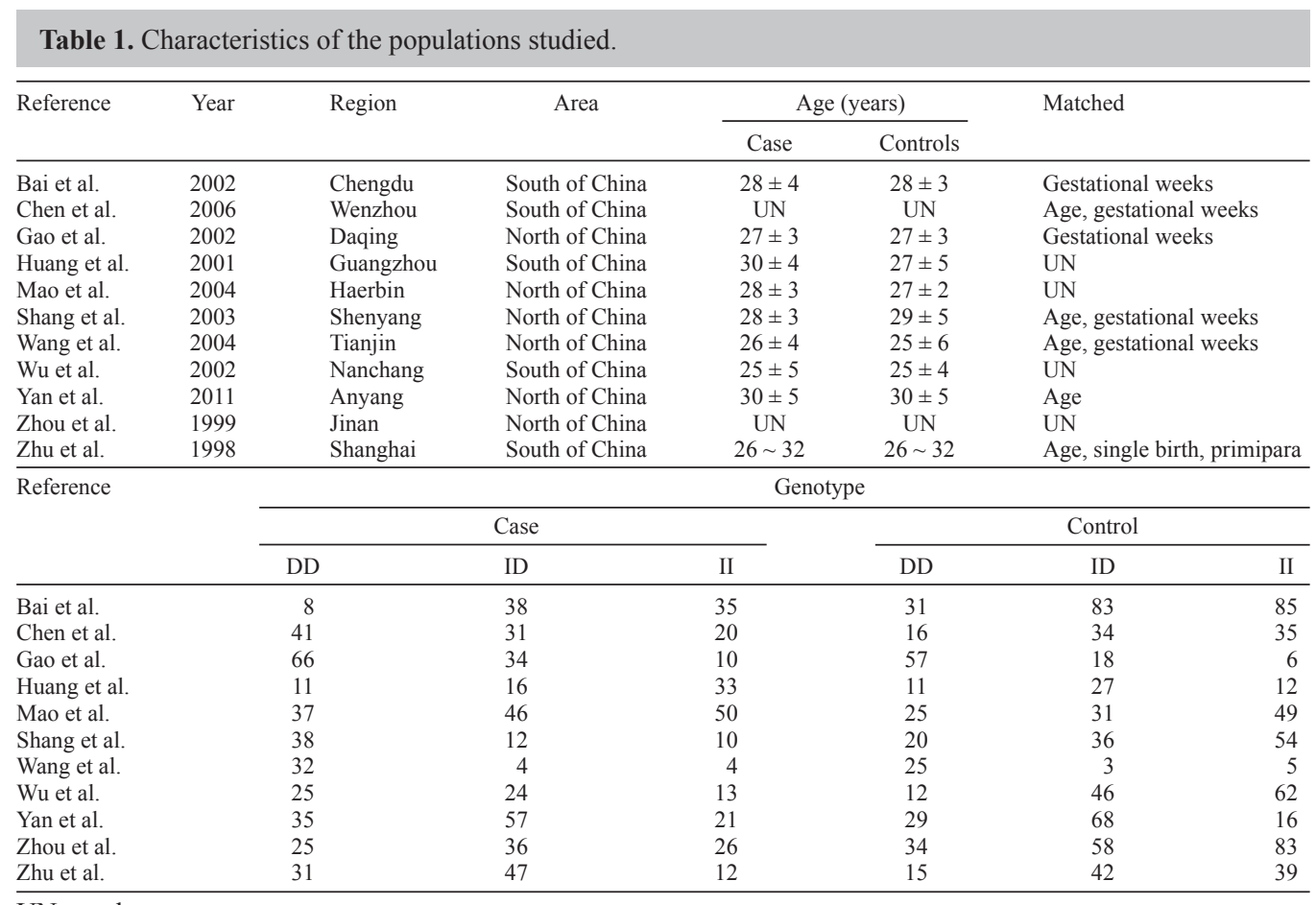

$\mathrm{UN}=$ unknown.

Consistent with the considerable variation in study designs, the test for heterogeneity was significant between study differences $(\mathrm{P}<0.001)$. Results of a random effects metaanalysis showed that the D allele was significantly associated with $\mathrm{PE}(\mathrm{OR}=1.93 ; 95 \% \mathrm{CI}=$ 1.19-3.12). Forest plots summarizing the effect of the D allele on PE in each of these studies are shown in Figure 1.

\section{Sensitivity and cumulative analyses}

In the sensitivity analyses, we deleted a single study each time we performed the meta-analysis. No individual study had an undue influence on the summary ORs for all contrasts. To identify the influence of the initial study on subsequent publications, a cumulative meta-analysis was conducted, which revealed substantial instability of the genetic effect over time. The two earliest studies demonstrated the most protective effect, immediately followed by studies published in 2001 and 2002 indicating the most significant results in the opposite direction (Table 2). 


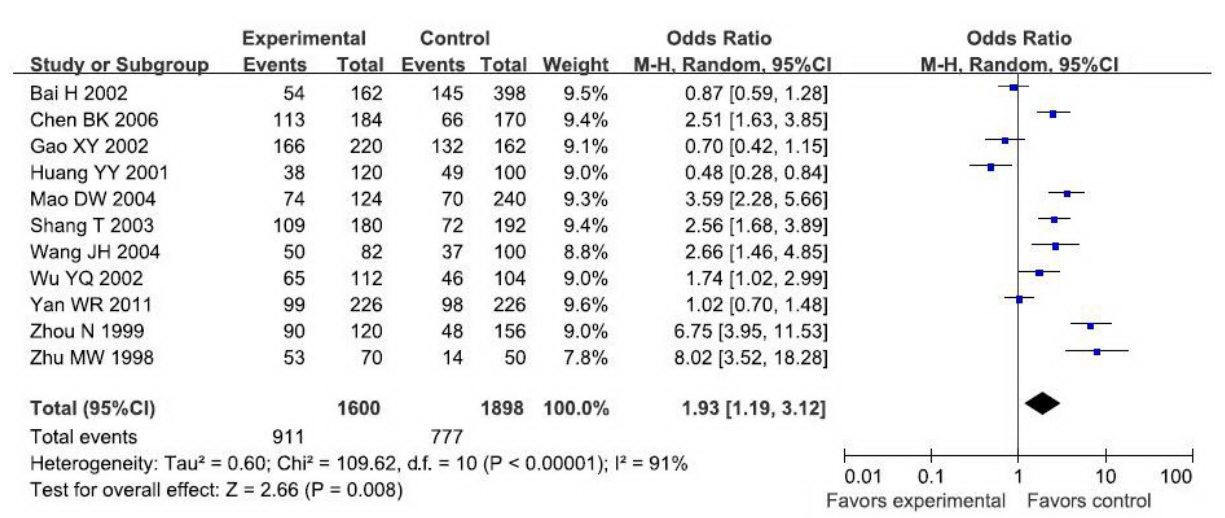

Figure 1. Contrast of D and I alleles. M-H. = Mantel-Haenszel estimator; $95 \% \mathrm{CI}=$ confidence interval; d.f. = degrees of freedom.

Table 2. Sensitivity and cumulative analyses.

\begin{tabular}{lllll}
\hline \multirow{2}{*}{ Study } & \multicolumn{2}{c}{ Sensitivity analysis } & \multicolumn{1}{c}{ Cumulative analysis } \\
\cline { 2 - 3 } & \multicolumn{1}{c}{ OR $(95 \% \mathrm{CI})$} & $\mathrm{P}$ & $2.14(0.58-7.93)$ & $\mathrm{P}$ \\
\hline Bai et al., 2002 & $2.10(1.26-3.50)$ & 0.005 & $2.06(1.22-3.50)$ & 0.26 \\
Chen et al., 2006 & $1.88(1.10-3.20)$ & 0.003 & $1.70(0.60-4.81)$ & 0.007 \\
Gao et al., 2002 & $2.13(1.30-3.51)$ & 0.001 & $2.93(0.45-19.31)$ & 0.32 \\
Huang et al., 2001 & $2.20(1.37-3.53)$ & 0.02 & $1.96(1.02-3.78)$ & 0.26 \\
Mao et al., 2004 & $1.81(1.09-3.01)$ & 0.02 & $1.80(0.87-3.71)$ & 0.04 \\
Shang et al., 2003 & $1.87(1.10-3.19)$ & 0.02 & $2.02(1.12-3.67)$ & 0.11 \\
Wang et al., 2004 & $1.87(1.11-3.14)$ & 0.01 & $1.70(0.72-3.99)$ & 0.02 \\
Wu et al., 2002 & $1.95(1.15-3.31)$ & 0.007 & $7.10(4.53-11.13)$ & \\
Yan et al., 2011 & $2.06(1.22-3.50)$ & 0.02 & $8.02(3.52-18.28)$ & $<0.008$ \\
Zhou et al., 1999 & $1.69(1.07-2.68)$ & 0.03 & & $<0.001$ \\
Zhu et al., 1998 & $1.71(1.06-2.76)$ & &
\end{tabular}

$\mathrm{OR}=$ odds ratio. $95 \% \mathrm{CI}=95 \%$ confidence interval.

\section{Subgroup analyses}

The history of the 5000-year Chinese civilization is a history of diverse ethnic admixture. The genetic background of Chinese Han might differ in southern and northern areas (Deng et al., 2004). Thus, we divided China into north and south along the Qinling Mountains and Huaihe River. Thereby, in subgroup analyses by geographic area, the magnitude of associations among populations from northern China was even stronger than those among populations in the south (Figure 2A).

Furthermore, a stratified analysis by study size, evaluated as the number of cases in each study $(\leq 100$ and $>100)$, showed a diminished effect as study size increased. A subgroup with a smaller sample size tended to have a larger $\mathrm{OR}(\leq 100$ : $\mathrm{OR}=2.33 ; 95 \% \mathrm{CI}=1.36-3.99$; $>100$ : $\mathrm{OR}=0.88 ; 95 \% \mathrm{CI}=0.61-1.26$; Figure $2 \mathrm{~B}$ ).

\section{Publication bias}

To assess publication bias, we calculated $\mathrm{N}_{\mathrm{fs}}$ at the level of 0.05 for each contrast. The $\mathrm{N}_{\mathrm{fs} 0.05}$ values for all contrasts were greater than the number of studies included in the meta-analysis. 
A

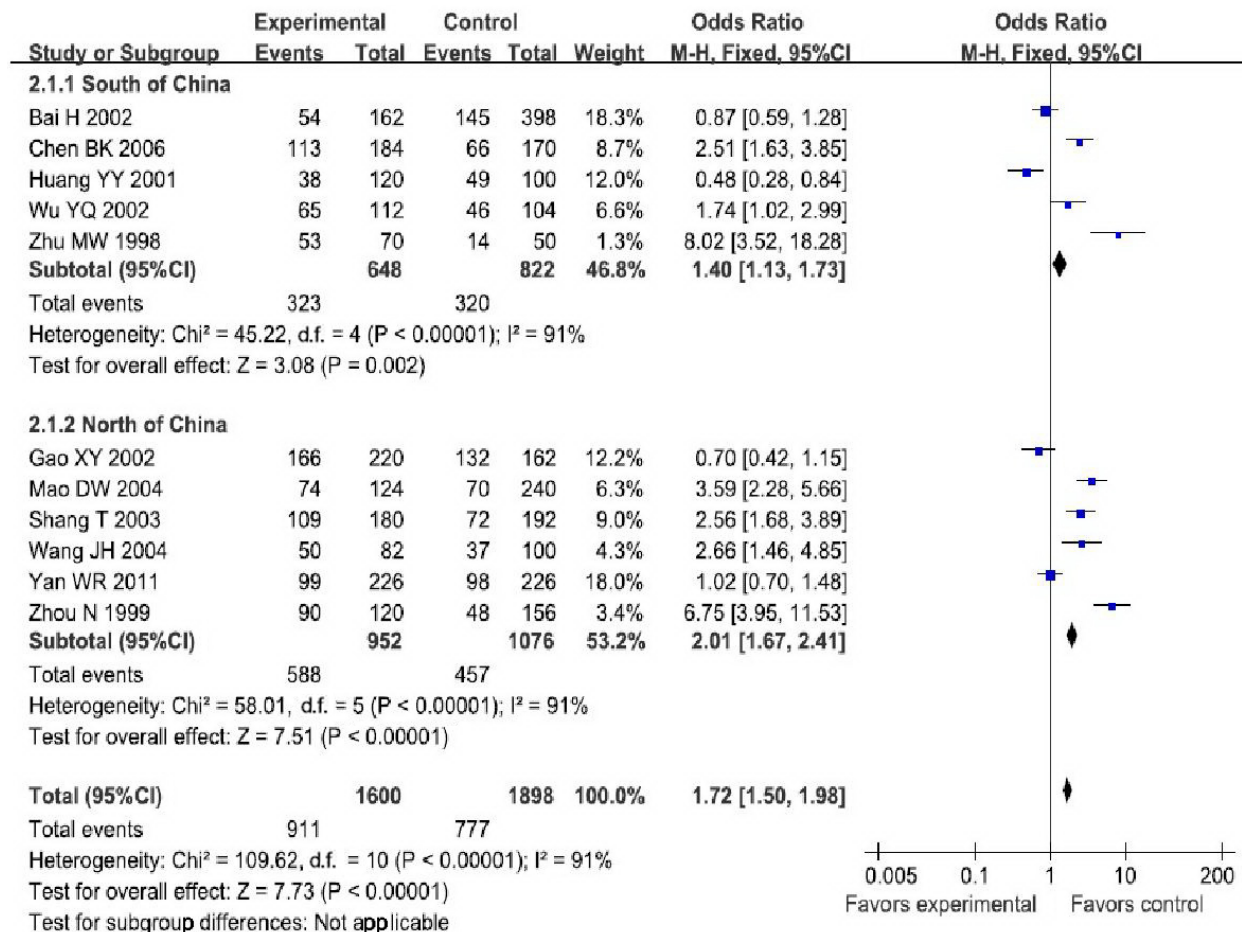

B

\begin{tabular}{|c|c|c|c|c|c|c|c|c|c|c|}
\hline \multirow{2}{*}{$\begin{array}{l}\text { Study or Subgroup } \\
2.2 .1 \leqslant 200\end{array}$} & $\begin{array}{l}\text { Case } \\
\text { Events }\end{array}$ & \multicolumn{3}{|c|}{ Control } & Weight & $\begin{array}{c}\text { Odds Ratio } \\
\mathrm{M}-\mathrm{H} \text {, Random, } 95 \% \mathrm{Cl}\end{array}$ & \multicolumn{4}{|c|}{$\begin{array}{c}\text { Odds Ratio } \\
\text { M-H, Random, } 95 \% \mathrm{Cl}\end{array}$} \\
\hline & & & & & & & & & & \\
\hline Bai H 2002 & 54 & 162 & 145 & 398 & $9.5 \%$ & $0.87[0.59,1.28]$ & & & & \\
\hline Chen BK 2006 & 113 & 184 & 66 & 170 & $9.4 \%$ & $2.51[1.63,3.85]$ & & & & \\
\hline Huang YY 2001 & 38 & 120 & 49 & 100 & $9.0 \%$ & $0.48[0.28,0.84]$ & & $\longrightarrow$ & & \\
\hline Mao DW 2004 & 74 & 124 & 70 & 240 & $9.3 \%$ & $3.59[2.28,5.66]$ & & & $\varpi$ & \\
\hline Shang T 2003 & 109 & 180 & 72 & 192 & $9.4 \%$ & $2.56[1.68,3.89]$ & & & & \\
\hline Wang JH 2004 & 50 & 82 & 37 & 100 & $8.8 \%$ & $2.66[1.46,4.85]$ & & & & \\
\hline Wu YQ 2002 & 65 & 112 & 46 & 104 & $9.0 \%$ & $1.74[1.02,2.99]$ & & & & \\
\hline Zhou N 1999 & 90 & 120 & 48 & 156 & $9.0 \%$ & $6.75[3.95,11.53]$ & & & $\rightarrow$ & \\
\hline Zhu MW 1998 & 53 & 70 & 14 & 50 & $7.8 \%$ & $8.02[3.52,18.28]$ & & & & \\
\hline Subtotal $(95 \% \mathrm{Cl})$ & & 1154 & & 1510 & $81.3 \%$ & $2.33[1.36,3.99]$ & & & & \\
\hline Total events & 646 & & 547 & & & & & & & \\
\hline Heterogeneity: $\mathrm{Tau}^{2}=$ & $61 ; \mathrm{Chi}^{2}$ & $=83.9$ & d.f. $=8$ & $(P<0$. & $.00001) ; 1^{2}$ & $=90 \%$ & & & & \\
\hline Test for overall effect & $=3.07$ & $=0.0$ & & & & & & & & \\
\hline $2.2 .2>200$ & & & & & & & & & & \\
\hline Gao XY 2002 & 166 & 220 & 132 & 162 & $9.1 \%$ & $0.70[0.42,1.15]$ & & & & \\
\hline Yan WR 2011 & 99 & 226 & 98 & 226 & $9.6 \%$ & $1.02[0.70,1.48]$ & & & & \\
\hline Subtotal $(95 \% \mathrm{Cl})$ & & 446 & & 388 & $18.7 \%$ & $0.88[0.61,1.26]$ & & & & \\
\hline Total events & 265 & & 230 & & & & & & & \\
\hline Heterogeneity: $\mathrm{Tau}^{2}=$ & .02; $\mathrm{Chi}^{2}$ & $=1.40$, & d.f. $=1$ & $P=0.2$ & $4) ; I^{2}=28$ & & & & & \\
\hline Test for overall effect & $=0.71$ & $P=0.4$ & & & & & & & & \\
\hline Total $(95 \% \mathrm{Cl})$ & & 1600 & & 1898 & $100.0 \%$ & $1.93[1.19,3.12]$ & & & & \\
\hline Total events & 911 & & 777 & & & & & & & \\
\hline $\begin{array}{l}\text { Heterogeneity: } \mathrm{Tau}^{2}= \\
\text { Test for overall effect }\end{array}$ & $\begin{array}{l}60 ; \mathrm{Chi}^{2} \\
=266\end{array}$ & $\begin{array}{l}=109 . \\
=0.0\end{array}$ & $\begin{array}{l}2, \text { d.f. }= \\
8)\end{array}$ & $10(P<$ & $0.00001)$ & $1^{2}=91 \%$ & 0.01 & $0.1 \quad 1$ & 10 & 100 \\
\hline Test for overall effect & $=2.661$ & $=0.0$ & & & & & Favors & experimental & Favors co & \\
\hline
\end{tabular}

Figure 2. Pooled odds ratio of developing preeclampsia for ACE D/I by area (A) and sample size (B). M-H. = Mantel-Haenszel estimator; $95 \% \mathrm{CI}=$ confidence interval; d.f. $=$ degrees of freedom. 
W.G. Zhong et al.

\section{DISCUSSION}

Through a comprehensive meta-analysis, we report a weak but still significant association of a common variance (I/D) in the $A C E$ gene and $\mathrm{PE}$ in Chinese women. The significant test of heterogeneity highlights a number of important differences between the studies that must be considered when interpreting the findings. We thereby undertook sensitivity and subgroup analyses to investigate the underlying causes. Our sensitivity analysis revealed that no individual study had an undue influence on the summary ORs for all contrasts. However, the subgroup analysis showed some interesting results. First, although geographic background does not seem to have obvious influence on the heterogeneity of our analysis, we still found that the association was enhanced among populations from northern China, whereas only a marginal association was detected among subjects from the south. Our results indicated that genetic background as well as varying dietary habits, such as salt consumption, may influence the heredity predisposition for hypertension in the Chinese population (Niu and Qi, 2011), and the same may be true in PE patents. Considering the relatively small sample sizes of each group in this study, our results should be explained casually, and cannot be directly extrapolated to the contribution of this polymorphism to PE in northern China.

Secondly, the meta-analysis revealed a diminishing summary risk estimate as study size increased. This result is concordant with those of Serrano et al. (2006), who have noted the presence of small-study bias in the meta-analysis of I/D polymorphism in the $A C E$ gene and $\mathrm{PE}$ among populations of varying ethnicities. The overall $\mathrm{P}$ value was significant in the present study, however, which is contrary to the finding of Serrano et al. (2006). Such inconsistency may be explained the by diverse ethnicity involved or the small number of studies with large sample size carried out in the Chinese population. Therefore, further research must be performed in Chinese women to confirm the result.

This meta-analysis should be interpreted within the context of its limitations. First, only published studies were included in the meta-analysis; thus, we cannot exclude the possibility of publication bias, although the results of statistical tests showed it to be unlikely. Second, all of the studies selected were hospital-based, cross-sectional studies, which cannot avoid potential selection bias. Third, in this study we analyzed only the association of I/D polymorphism in the $A C E$ gene with $\mathrm{PE}$ and did not evaluate other polymorphisms in this gene and other targeted genes that might contribute to PE, such as angiotensin II type 1 receptor (Salimi et al., 2011). Last but not least, it has been suggested that both maternal and fetal genetic polymorphism should be considered in studies of the development of PE (Vefring et al., 2010), but we meta-analyzed only the data from mothers, which eliminated the few data of fetuses in the included publications.

The current meta-analysis suggested that the $\mathrm{D}$ allele of the $A C E$ gene is most likely associated with the susceptibility to PE in Chinese women, whereas significant heterogeneity was evident across individual studies. The subgroup analysis indicated the variation between studies from different regions and with varying sample sizes. Owing to the above-mentioned limitations, the findings should be verified by further research with large sample sizes.

\section{ACKNOWLEDGMENTS}

Research supported by the Self-Innovation Program of the Health System of the Putuo 
District of Shanghai (2008), National Natural Science Foundation of China (\#30771184), the National Natural Science Foundation of China (\#81000037) and the Natural Science Foundation of Shanghai (\#10ZR1425100), and Shanghai Municipal Health Bureau Foundation (\#2010Y052).

\section{REFERENCE}

Admiraal PJ, Derkx FH, Danser AH, Pieterman H, et al. (1990). Metabolism and production of angiotensin I in different vascular beds in subjects with hypertension. Hypertension 15: 44-55.

Bai H, Liu X, Liu R, Liu Y, et al. (2002). Angiotensinogen and angiotensin-I converting enzyme gene variations in Chinese pregnancy induced hypertension. Ниа Xi Yi Кe Da Хие Хие Ваo 33: 233-237.

Bouba I, Makrydimas G, Kalaitzidis R, Lolis DE, et al. (2003). Interaction between the polymorphisms of the reninangiotensin system in preeclampsia. Eur. J. Obstet. Gynecol. Reprod. Biol. 110: 8-11.

Chen B, Zhuo J and Zhou L (2006). Study on the polymorphism of angiotensin I-converting enzyme gene in pregnancy·induced hypertension syndrome. Iian Yan Yi Xue 21: 39-41.

Deng W, Shi B, He X, Zhang Z, et al. (2004). Evolution and migration history of the Chinese population inferred from Chinese Y-chromosome evidence. J. Hum. Genet. 49: 339-348.

Esplin MS, Fausett MB, Fraser A, Kerber R, et al. (2001). Paternal and maternal components of the predisposition to preeclampsia. N. Engl. J. Med. 344: 867-872.

Galao AO, de Souza LH, da Costa BE, Scheibe RM, et al. (2004). Angiotensin-converting enzyme gene polymorphism in preeclampsia and normal pregnancy. Am. J. Obstet. Gynecol. 191: 821-824.

Gao Y, Qiu X, Ye F, Chen L, et al. (2002). Research on the deletion/insertion polymorphism of angiotensin converting enzyme gene in pregnancy induced hypertension women. Zhong Guo Fu You Bao Jian 17: 738-740.

He G, Liu X, Fan P, Liu R, et al. (2009). The C825T polymorphism in the G-protein beta 3 subunit gene in Chinese patients with preeclampsia. Hypertens. Pregnancy 28: 156-167.

Huang Y, Liao B and Sun X (2001). Study on the relation between the angiotensin converting enzyme gene and pregnancy induced hypertension. Zhonghua Fu Chan Ke Za Zhi 36: 15-17.

Kaur R, Jain V, Khuller M, Gupta I, et al. (2005). Association of angiotensin-converting enzyme gene polymorphism with pregnancy-induced hypertension. Acta Obstet. Gynecol. Scand. 84: 929-933.

Mao W, Li K and Zhao Y (2004). Study on MTHFR gene and ACE gene polymorphisms in pregnancy-induced hypertension. Chin. J. Perinat. Med. 7: 24.

Niu W and Qi Y (2011). Association of alpha-adducin and G-protein beta3 genetic polymorphisms with hypertension: a meta-analysis of Chinese populations. PLoS One 6: e17052.

Rohacs T, Nagy G and Spat A (1997). Cytoplasmic $\mathrm{Ca}^{2+}$ signalling and reduction of mitochondrial pyridine nucleotides in adrenal glomerulosa cells in response to $\mathrm{K}^{+}$, angiotensin II and vasopressin. Biochem. J. 322 (Pt 3): 785-792.

Salimi S, Mokhtari M, Yaghmaei M, Jamshidi M, et al. (2011). Association of angiotensin-converting enzyme intron 16 insertion/deletion and angiotensin II type 1 receptor A1166C gene polymorphisms with preeclampsia in South East of Iran. J. Biomed. Biotechnol. 2011: 941515.

Schmieder RE, Hilgers KF, Schlaich MP and Schmidt BM (2007). Renin-angiotensin system and cardiovascular risk. Lancet 369: 1208-1219.

Serrano NC, Diaz LA, Paez MC, Mesa CM, et al. (2006). Angiotensin-converting enzyme I/D polymorphism and preeclampsia risk: evidence of small-study bias. PLoS Med. 3: e520.

Shang T, Wang Y, Sun W and Sun F (2003). Relationship of ACE and AT1R and pregnancy induced hypertension. Chin. J. Obstet. Gynecol. 33: 102-103.

Tan CY, Chong YS, Loganath A, Chan YH, et al. (2009). Possible gene-gene interaction of KIR2DL4 with its cognate ligand HLA-G in modulating risk for preeclampsia. Reprod. Sci. 16: 1135-1143.

Tiret L, Rigat B, Visvikis S, Breda C, et al. (1992). Evidence, from combined segregation and linkage analysis, that a variant of the angiotensin I-converting enzyme (ACE) gene controls plasma ACE levels. Am. J. Hum. Genet. 51: $197-205$.

Vefring HK, Wee L, Jugessur A, Gjessing HK, et al. (2010). Maternal angiotensinogen (AGT) haplotypes, fetal renin (REN) haplotypes and risk of preeclampsia; estimation of gene-gene interaction from family-triad data. BMC Med. Genet. 11: 90.

Wang J, Bu T, Wang Y and Cheng P (2004). Relationship between insertion/deletion polymorphism of angiotensin converting enzyme gene and pregnancy-induced hypertension syndrome. Tian Jin Yi Yao 32: 339-341. 
WHO (2005). World Health Report: Make Every Mother, and Child Count. World Health Organization, Geneva.

Wu Y, Cheng K, Su H, Cheng X, et al. (2002). Association of angiotensin converting enzyme polymorphism and preeclampsia. Zhonghua Fu Chan Ke Za Zhi 37: 301.

Yan W, Kulane A, Xiang P, Li Z, et al. (2011). Maternal and fetal angiotensin-converting enzyme gene insertion/deletion polymorphism not associated with pregnancy-induced hypertension in Chinese women. J. Matern. Fetal Neonatal Med. 24: 1119-1123.

Zhou N, Yu P, Chen J, Huang H, et al. (1999). Detection of insertion/deletion polymorphism of angiotensin converting enzyme gene in preeclampsia. Zhonghua Yi Xue Yi Chuan Xue Za Zhi 16: 29-31.

Zhu M, Xia Y and Cheng W (1998). Study on a deletion polymorphism of the angiotensin converting enzyme gene in pregnancy induced hypertension. Zhonghua Fu Chan Ke Za Zhi 33: 83-85. 